\title{
Pasture renewal practices, experiences and attitudes: a comparison over time
}

\author{
K. RIJSWIJK ${ }^{1}$ and R. BRAZENDALE ${ }^{2}$ \\ ${ }^{1}$ Wageningen University, Postbus 9101, 6700 HB, Wageningen, The Netherlands \\ ${ }^{2}$ DairyNZ, Massey University, Private Bag 11-222, Palmerston North, New Zealand \\ kelly.rijswijk@wur.nl
}

\begin{abstract}
In 2010, Waikato and Bay of Plenty dairy farmers were surveyed by the Pasture Improvement Leadership Group (PILG) to better understand their attitudes, confidence and ability to make informed decisions on their pasture renewal practices. To assess changes in farmer behaviour towards pasture renewal and to measure the impact of the PILG, the survey was repeated in 2015. In comparison to 2010, the 2015 survey results were more positive. Farmers' confidence, attitude and satisfaction with their ability to successfully renew pasture, and to improve pasture performance have increased. However, some scepticism remains about time investment and the financial return from pasture renewal. These results suggest that the PILG aim of ensuring that consistent messages relating to pasture renewal are provided to farmers, appears to have been met. Farmers indicated in the 2015 survey that not only is there now better information available in comparison to 2010 , the messages are also more consistent across the industry.
\end{abstract}

Keywords: pasture renewal, pasture performance, farmer confidence, farmer attitude, communication

\section{Introduction}

In 2010, following 2 years of summer drought, New Zealand farmers were dissatisfied with pasture persistence and receiving mixed messages about pasture renewal (Kerr 2011). A suite of initiatives to understand and respond to the problem was developed by DairyNZ. The formation of the Pasture Improvement Leadership Group (PILG) was one such initiative, bringing together representatives from the seed production industry, seed retailers, agricultural contractors, researchers and farmers, aiming to develop and promote messages relating to pasture renewal and provide a quality control function for those messages.

One of the first actions of the PILG, was to conduct a survey of Waikato and Bay of Plenty dairy farmers to better understand their attitude, confidence and ability to make informed decisions on their pasture renewal practices (Kelly et al. 2011). This survey, conducted in 2010, showed that there was considerable confusion amongst respondents around many core aspects and components of pasture renewal. This confusion resulted in a lack of confidence amongst farmers to make the right grass cultivar and endophyte choices; low satisfaction with the persistence of renewed pastures; difficulties in finding useful sources of information on pasture renewal; and a need to be provided with the evidence that appropriate pasture renewal justifies the investment of the time and cost (Kelly \& Smith 2010).

To assess changes in farmer behaviour around pasture renewal and to measure the impact of the PILG, the survey was repeated in 2015. This paper discusses the 2015 survey results and changes since the 2010 survey, and is largely based on a report by Rijswijk \& Rhodes (2015).

\section{Methods}

To enable a comparison between the 2010 and 2015 surveys, the approach and content of the 2015 survey was largely made consistent with that of the first, with a few additional questions. The 2015 survey was divided into seven sections: 1 . Personal information; 2. Pasture renewal practices and experiences; 3 . Pasture performance; 4. Farmers' attitudes towards pasture renewal; 5. Perceived changes in comparison to 2010; 6. Information sources; and 7. Farmers' awareness of the PILG. The characteristics of the 2015 survey respondents, their farms and pasture renewal practices were also similar to the 2010 survey respondents.

The 2015 survey was distributed via email to 3437 dairy farmers in the Waikato and Bay of Plenty regions, using the DairyNZ database. This database identified 3717 different farms, some of which were owned by the same people. Due to the risk of survey fatigue, duplications of email addresses were removed from the email list. The farms surveyed were selected on the basis of availability of an email address, as well as the associated level of decision-making power (e.g., farm owners, owner/operators, managers and share-milkers). The 2015 survey was sent to 809 fewer farmers than the 2010 survey. In 2010, 3746 farmers received a survey via email and another 500 were randomly selected for a postal survey, totalling 4246 potential respondents (Kelly \& Smith 2010). Unlike the 2010 survey, no supplementary postal surveys were distributed in 2015. The data received from the 2015 survey were analysed using Microsoft Excel. 


\section{Results and Discussion}

A total of 376 responses to the 2015 survey were received, representing $11 \%$ of the total sample. Of these 376 responses, 319 farmers completed the survey and another 57 partially completed it. For every question, the total number of responses were used as not every question was applicable to all respondents, allowing the partially completed surveys to be included. The 2010 survey resulted in 776 responses, giving an 18\% response rate (Kelly \& Smith 2010).

The average age of 2015 respondents was 53 years; $84 \%$ of them were male; and the majority $(81 \%)$ had over 15 years' experience in dairy farming. In total, $82 \%$ of these respondents were owners, co-owners or owner/operators. The respondents in 2010 had an average age of 56 years; $89 \%$ were male; the majority also had over 15 years' experience; and they were mainly farm owners (Kelly \& Smith 2010).

\section{Pasture renewal practices and experiences}

The majority of the 2015 respondents $(71 \%)$ renewed their pastures in the last 12 months. Of those respondents, $86 \%$ had renewed up to $25 \%$ of their pastures in the last 12 months, and 3\% renewed more than $50 \%$ of their farm. This response was similar to the 2010 survey. The main difference was that in 2010 a slightly larger group renewed more than $50 \%$ of their pastures (Kelly \& Smith 2010). The preferred method for renewing their pastures was grass-crop-grass, followed by undersowing of grass seed. Those farmers who renewed higher percentages of their pastures mainly chose undersowing. Again, these results were similar to the 2010 survey results (Kelly \& Smith 2010) (Table 1).

The farmers were also asked about their level of confidence to make pasture renewal decisions (1: not at all confident, 7: very confident). Two extra statements were added to this question for the 2015 survey (Figure 1), to capture a wider spectrum of activities that a farmer needs to consider with respect to pasture renewal. The additional statements were 'identifying paddocks for pasture renewal' and 'selecting the most suitable seed treatment'. Overall, confidence levels reported in 2015 had increased slightly in comparison to 2010 with the exception of 'appropriate management during the establishment phase' which decreased from 5.8 in 2010 to 5.6 in 2015. Interestingly, the highest level of confidence related to 'identifying paddocks for pasture renewal'. Although respondents were not asked why they indicated a certain level of confidence for a certain pasture renewal activity, the high level of confidence for identifying paddocks could be because they make that decision on their own, potentially with help of tools to score the condition of pastures, as they were often the only person to see the paddocks. All the other activities tended to involve another person such as a seed retailer and/or a contractor.

\section{Pasture performance}

The 2015 respondents claimed high levels of satisfaction with their current ability to renew pastures; $79 \%$ were either satisfied to very satisfied. This high level of satisfaction represented an increase compared to 2010 when $60 \%$ of respondents were satisfied. The percentage of respondents expressing a level of dissatisfaction decreased, correspondingly, from $25 \%$ in 2010 (Kelly \& Smith 2010) to 12\% in 2015.

The 2015 farmers' level of satisfaction with pasture performance experienced after 1,2 or 3 years decreased over the years (Figure 2). After year one, $83 \%$ ( $\mathrm{n}=299$ respondents) mentioned that they were satisfied (levels 5 to 7); after 2 years this dropped to $66 \%$ ( $\mathrm{n}=293$ respondents); and after 3 years fell to $51 \%$ ( $\mathrm{n}=290$ respondents). There was a corresponding increase of dissatisfaction (levels 1 to 3 ) from $6 \%$ in Year 1 to $28 \%$ in Year 3. However, an increase in level 4, 'neutral' (going from 11\% in Year 1 to $20 \%$ in Year 3 ) shows that respondents found it harder to comment on their level of satisfaction with the renewed pasture as the age of pasture increased. In 2010, a similar trend existed (Figure 3), however, the increase in the level of dissatisfaction over time was much stronger than the 2015 results show, with barely any increase in neutral answers (Kelly \& Smith 2010).

Table 1 Percentage of total farm area renewed in the past 12 months and number of respondents using different pasture renewal techniques. (2010 survey: 395 respondents; 2015 survey: 268 respondents).

\begin{tabular}{|c|c|c|c|c|c|c|}
\hline \multirow[t]{2}{*}{$\%$ of farm area renewed } & \multicolumn{2}{|c|}{ Number using grass-grass } & \multicolumn{2}{|c|}{ Number using grass-crop-grass } & \multicolumn{2}{|c|}{ Number using undersowing } \\
\hline & 2010 & 2015 & 2010 & 2015 & 2010 & 2015 \\
\hline $1-10$ & 36 & 18 & 94 & 75 & 35 & 25 \\
\hline $11-25$ & 22 & 11 & 57 & 58 & 59 & 41 \\
\hline $26-50$ & 4 & 4 & 11 & 7 & 37 & 19 \\
\hline $51-75$ & 3 & 1 & 1 & 1 & 16 & 2 \\
\hline $75-100$ & 1 & 0 & 3 & 1 & 16 & 5 \\
\hline
\end{tabular}


In 2015 , farmer respondents were also asked about their expectations in terms of the number of years that a new pasture would perform before having to be renewed. On average, the farmers expected a pasture to perform for 11 years. However, $56 \%$ expected a pasture to perform between 6 and 10 years. The high expectation about pasture performance contrasts with respondents' actual experiences, as reflected by the downward trend in the levels of satisfaction as pasture age increased.

\section{Attitude to pasture renewal}

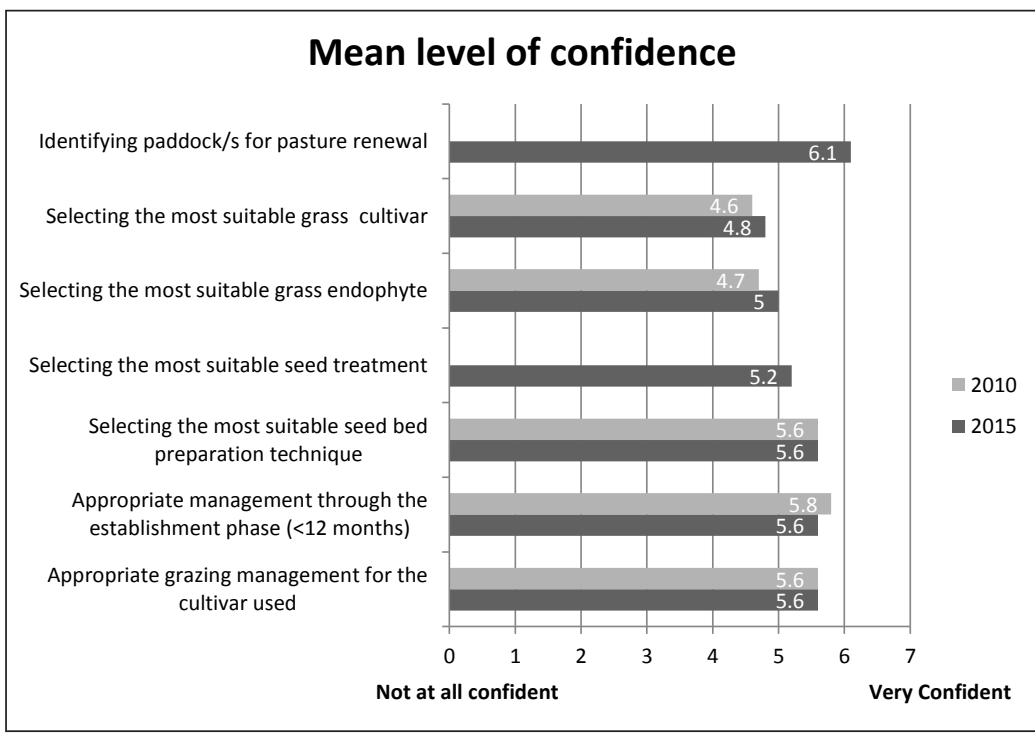

The survey results showed

Figure 1 Mean level of confidence in pasture renewal practices in 2010 and 2015. 1= not at all confident, 7 = very confident

\section{that farmers who do renew}

pasture have a more positive attitude towards the different aspects of pasture renewal, such as availability of a suitable cultivar, financial return and information access, than those who did not renew their pastures (Figure 4). A similar trend was seen in 2010 (Figure 5). The topics that farmers who did not renew pastures were least positive remain the same as in 2010: time investment, financial return and the fact that they do not believe that pasture renewal fits with their current farm system. However, there is general improvement of attitudes of both groups of farmers (who did and did not renew) towards different aspects of pasture renewal in comparison to 2010.

Farmers in 2015 were also asked what they perceived to be the main issues related pasture renewal. These issues included: persistence (113 mentions), drought (84 mentions), weeds (59 mentions) and pests (48 mentions). In 2010 , only the weeds category was not perceived as a main issue; persistence (202 mentions) and drought (200 mentions) were important and black beetle damage (143 mentions) was such a serious problem that it received its own category (Kelly \& Smith 2010).

\section{Sources of information}

The perceived usefulness of a range of different information sources that farmers might use in relation to pasture renewal was rated by respondents (1: not at all useful, 7: very useful). In comparison to the 2010 survey, a number of different types of information sources were added to the list of potential providers, such as DairyNZ publications; DairyNZ's Forage

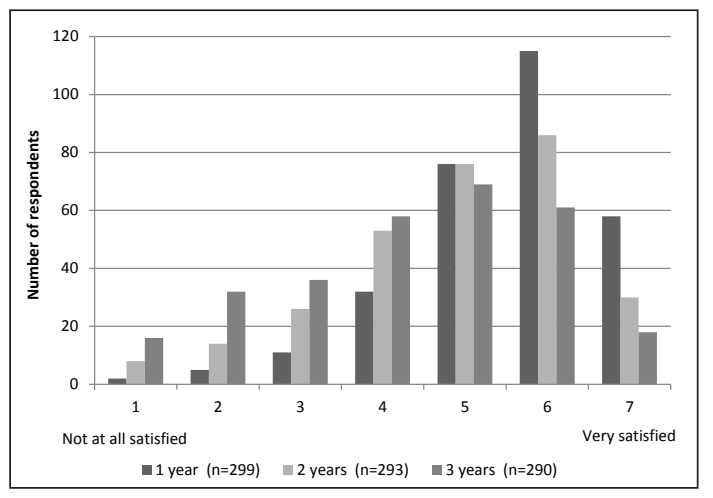

Figure 2 Levels of satisfaction with the performance of renewed pastures after 1,2 and 3 years from sowing (2015 survey). 1= not at all satisfied, $7=$ very satisfied.

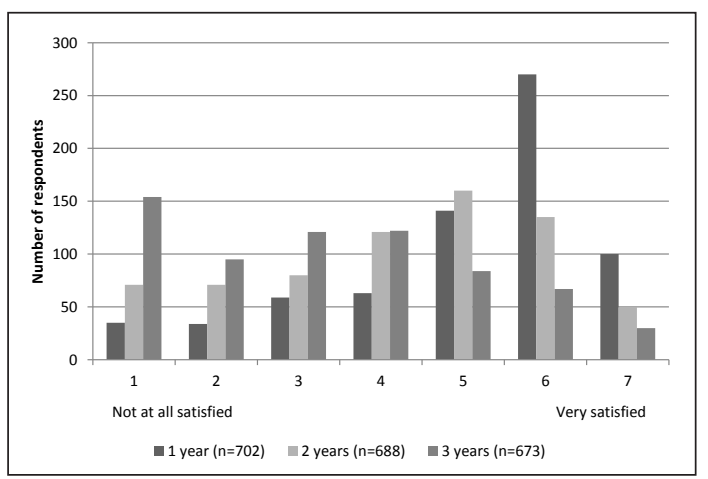

Figure 3 Levels of satisfaction with the performance of renewed pastures after 1,2 and 3 years $(2010$ survey). $1=$ not at all satisfied, $7=$ very satisfied. 


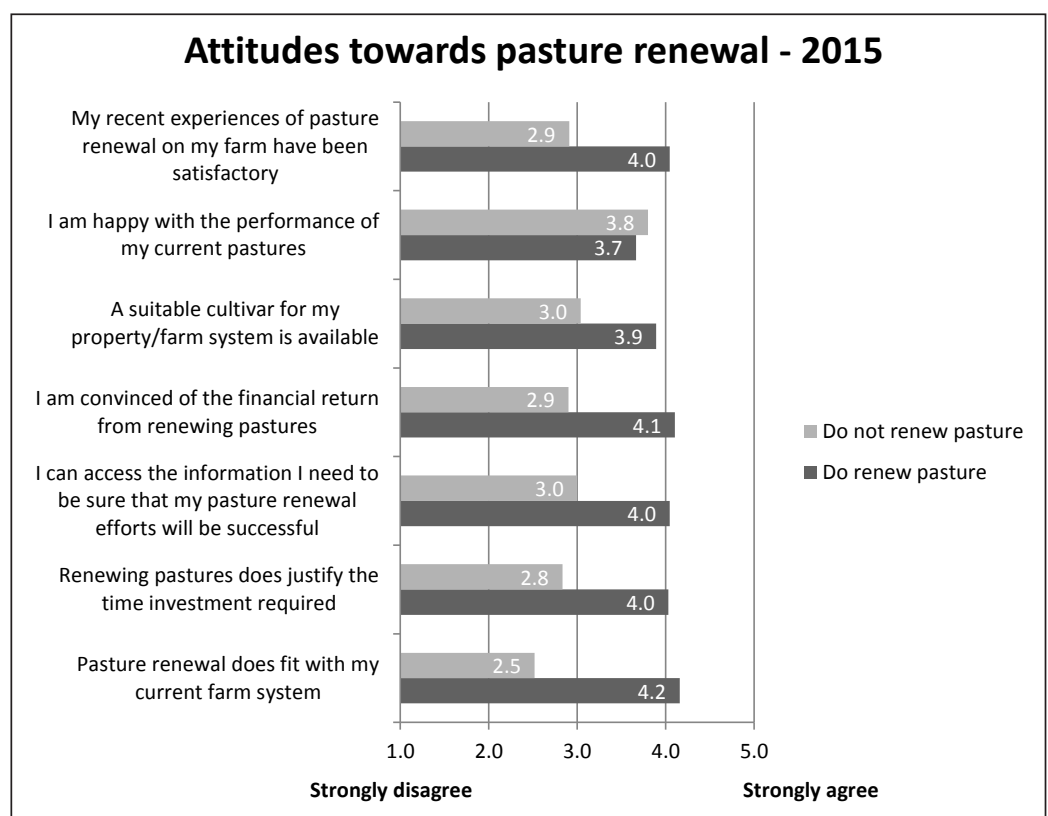

Figure 4 Attitude towards pasture renewal (2015 survey). $1=$ strongly disagree, $5=$ strongly agree.

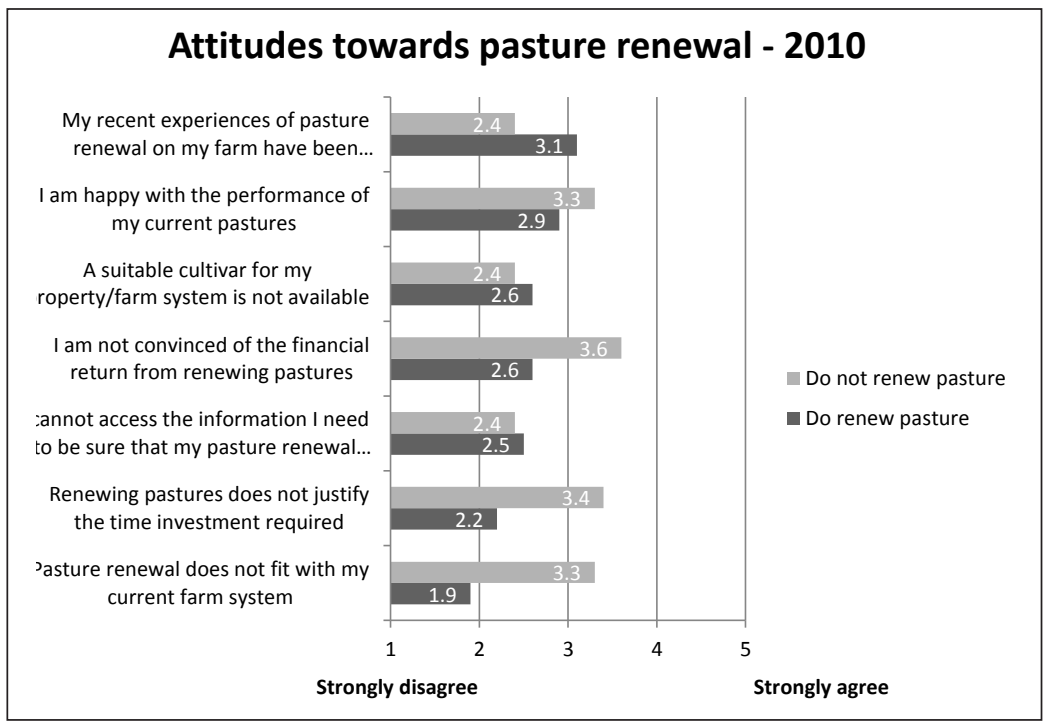

Figure 5 Attitude towards pasture renewal (2010 survey) (Kelly \& Smith 2010). 1= strongly disagree, 5 = strongly agree.

Value Index; respondents' own university study or training; the Pasture Renewal Charitable Trust website; and Pestweb. Other information sources have been renamed, such as DairyNZ consulting officers (COs) are now called DairyNZ staff. This acknowledges that farmers also may talk to other DairyNZ staff, not just COs, about pasture renewal. Seed merchants have been renamed as seed retailers (Figure 6).

The information sources deemed to have the highest level of usefulness in 2015 were seed retailers (5.2), researchers and scientists (4.9), other local farmers (4.9), farm consultants (4.8) as well as respondents' own university study or training (4.8). In 2010, this list was dominated by similar information sources, although in a different order: farm consultants (4.9), seed retailers (4.7) and researchers and scientists (4.7) (Figure 6). Mail publications, which in 2015 was referred to as 'other', saw the biggest decrease in usefulness by 0.8 points. Of the newly added information sources the respondents' own university study or training (4.8) and DairyNZ's Forage Value Index (4.6) scored highest. Overall, the perceived level of usefulness of information sources has increased, with more information sources reaching the highest levels of usefulness.

\section{Contribution of PILG to} changes since 2010

To measure change over time in terms of pasture renewal practices, experiences and attitudes, the farmers were asked to rank their level of agreement against three statements. The first statement, 'compared to 2010 there is now better information available about pasture renewal', saw 54\% of farmers $(n=326)$ either agree or strongly agree with it. Another $37 \%$ of the farmers were neutral about this statement.

The second statement, 'compared to 2010, the messages about pasture renewal are more consistent across the industry' saw more respondents rank it as neutral ( $43 \%$ of 326 farmers), $49 \%$ agreed or strongly agreed with this statement. This result suggests that not only was there better information available for farmers, but that the information itself is captured in a more 
consistent way across the industry.

The third statement, 'compared to 2010 , I have made significant changes in how I renew my pastures' saw 36\% of the 323 farmers respond neutrally, another $36 \%$ agreed or strongly agreed with this statement, but $22 \%$ either disagreed or strongly disagreed. This greater distribution in responses could be explained by the farmers' increased feelings of confidence to make decisions about pasture renewal activities. Confident farmers may for instance think there is less need to make changes to their current pasture renewal practices, as they perceive their activities to go well.

\section{Conclusion}

In comparison to 2010, the 2015 survey results are more positive. Farmers' confidence levels have increased, especially in relation to selecting paddocks for renewal. The level of satisfaction with farmers' current abilities to renew pasture, and the pasture performance itself have also increased. The farmers' attitude towards various aspects of pasture renewal also improved, however, some farmers remained sceptical about the time investment, financial return, and the fit of pasture renewal with their farm system. The aim of the PILG, to ensure consistent messages relating to pasture renewal were disseminated, appears to have been met as respondents indicated that not only is there now better information available in comparison to 2010, but also that the messages were more consistent across the industry. These results indicate improvements to the quality of communication between the various players in the field of pasture renewal, such as seed retailers, farmers and researchers (see Rijswijk 2013).

Collecting longitudinal survey data on farmers' attitudes to and practices around pasture renewal is an important function for the PILG. These data are valuable to the dairy industry as it quantifies progress in addressing pasture performance issues and helps prioritise future investment. Progress has been demonstrated in providing useful information to farmers about pasture renewal practices and the consistency of messages has improved. However, pasture persistence continues to a major concern for farmers.

Research is currently underway to further understand the drivers of pasture persistence (Lee et al. 2013) and an economic value for persistence will be added to the future Forage Value Index (Chapman et al. 2012). As results from this research become available the PILG has an ongoing role in reaching agreement with industry partners on the key messages for dairy farmers. Communication channels established by the PILG will be activated to ensure these messages are delivered clearly and consistently to a broad dairy farmer audience.

\section{ACKNOWLEDGEMENTS}

The authors wish to thank all dairy farmers who contributed to both surveys, as well as DairyNZ for funding this work. The authors also would like to acknowledge all past and present members of the PILG. 


\section{REFERENCES}

Chapman, D.F.; Bryant, J.R.; McMillan, W.H.; Khaembah, E.N. 2012. Economic values for evaluating pasture plant traits. Proceedings of the New Zealand Grassland Association 74: 209-216.

Kelly, S.; Smith, E. 2010. Pasture renewal in the Waikato and Bay of Plenty regions. Client report prepared for DairyNZ by AgResearch Ltd, New Zealand.

Kelly, S.; Smith, E.; Brazendale, R. 2011. Pasture renewal in the Waikato and Bay of Plenty regions: An overview of farmer practice, experience and attitude. Pasture Persistence Symposium. Grassland Research and Practice Series 15: 21-24.

Kerr, G.A. 2011. Introduction. Pasture Persistence Symposium. Grassland Research and Practice Series 15: 1.
Lee, J.; Thom, E.; Chapman, D.; Wynn, K.; Waugh, D.; Rossi, L. 2013. Ryegrass seeding rate alters plant morphology and size - possible implications for pasture persistence. pp. 311-313. In: Proceedings of the 22nd International Grasslands Congress.

Rijswijk, K. 2013. Interactions between players in the field of pasture renewal. Proceedings of the New Zealand Grassland Association 75: 221-226.

Rijswijk, K.; Rhodes, H. 2015. Pasture renewal in the Waikato and Bay of Plenty regions: a comparison between 2010 and 2015 farmer surveys. Client report prepared for DairyNZ by AgResearch Ltd., New Zealand. 